\title{
VIOLÊNCIA INFANTIL: atuação do psicólogo no processo de auxílio à criança
}

DOI: $10.22289 / 2446-922 X . V 4 N 1 A 4$

\author{
Jessica Cristina Tiago da Silva ${ }^{1}$ \\ Sara Cristina de Assunção Melo
}

\section{RESUMO}

A violência infantil é uma realidade preocupante para a sociedade atual, pois pode suscitar problemas de grande magnitude crianças e adolescentes além de consequências que geralmente se estendem à vida adulta. $O$ trabalho do psicólogo pode contribuir na prevenção e na minimização dos danos. O estudo apresenta uma pesquisa bibliográfica cujo objetivo foi analisar publicações sobre a violência infantil e assinalar possibilidades de atuação do psicólogo diante dessa realidade. A pesquisa permite uma maior compreensão da violência infantil e das contribuições do psicólogo. Fica evidente a necessidade da atuação coletiva da sociedade e de distintos profissionais para a efetiva prevenção da violência contra crianças e adolescentes, auxílio na redução dos prováveis danos e para a diminuição dos alarmantes índices de ocorrência de casos.

Palavras chaves: Infância; Violência; Psicologia.

\section{ABSTRACT}

The children abuse is a worrying reality to the modern society, because it can evoke big magnitude problems to children and teenagers beyond consequences that usually extend to adulthood. The work of the psychologist can contribute on the prevention and softening of the damage. The study presents a bibliographical review which objective was to analyze publications about the children abuse and to point out possibilities of performance to the psychologist against this reality. The review allows a bigger comprehension of children abuse and the contributions of the psychologist. Is evident the necessity of collective performance from the society and different professionals to the effective prevention of violence against children and teenagers, the help on softening of likely damage and the reduction of alarming occurrence of cases.

Key words: Childhood; Violence; Psychology.

\footnotetext{
${ }^{1}$ Endereço eletrônico de contato: jessicacristina.silva@ymail.com Recebido em 22/10/2017. Aprovado pelo Conselho Editorial e aceito para publicação em 15/11/2017.
} 


\section{INTRODUÇÃO}

A infância é concebida enquanto período de formação integral do sujeito, diversos autores defendem a necessidade de um ambiente precisa propicio ao desenvolvimento harmônico e saudável.

Nos dizeres de Papalia (2013) o ser humano é bastante complexo o que dificulta muito a divisão de sua vida em fases, pois essas não são plenamente definidas apenas por idades, dependendo de inúmeros fatores, dentre os quais se destacam os aspectos sociais, culturais e físicos. Para a autora os períodos do ciclo vital encontrados na literatura correspondem a uma construção social, cujos ideais acerca da natureza da realidade são aceitos pelos integrantes de uma determinada sociedade numa determinada época cujas bases estão nas percepções ou suposições subjetivas comuns.

O autor salienta que só recentemente as sociedades industriais adotaram o conceito de adolescência como um período de desenvolvimento, o mesmo ocorreu com a meia-idade, antes inerente à vida adulta, sobretudo devido ao fato de uma expectativa de vida mais curta. Isso ainda ocorre em algumas sociedades pré-industriais, em que os papéis sociais não mudam apreciavelmente entre a idade adulta e a velhice (Papalia, 2013).

Devido à diversidade de concepção acerca da definição de infância, nesse trabalho tal fase obedece à legislação brasileira. O Art. $2^{\circ}$ da LEI № 8.069 considera criança, para os efeitos da referida Lei, a pessoa até doze anos de idade incompletos, e adolescente, a pessoa que tem entre doze e dezoito anos de idade. (BRASIL, 1990). Conforme essa legislação a criança e o adolescente devem ter acesso a todos os direitos fundamentais próprios dos seres humanos sem prejuízo de sua proteção integral.

Acerca da temática Sonego e Kolody (2012) advertem que, no Brasil, o Estatuto da Criança e do Adolescente (BRASIL, 1990) prescreve no seu artigo 5우 que nenhuma criança ou adolescente deve ser objeto de qualquer forma de negligência, exploração, violência, crueldade, discriminação e opressão, ou mesmo punido na forma da lei por ação ou omissão, aos seus direitos fundamentais. Porém, a violência aflige as diversas e distintas camadas sociais. Ela atinge de forma injusta, cruel, e indiscriminada, as crianças e adolescentes, seja nas ruas, nos logradouros públicos, nos lares pelos maus-tratos, espancamentos, torturas e abusos sexuais, nas escolas ou instituições pela estigmatização e/ou marginalização, dentre outras formas.

Sonego e Kolody (2012) consideram evidente a amplitude com que a violência permanece na vida dos meninos e meninas brasileiras bem como as vastas as formas com

Rev. Psicol Saúde e Debate. Fev., 2018:4(1):61-84. 
que pode se manifestar a violência dirigida a esses sujeitos, refletindo aspectos históricos, culturais, estruturais e conjunturais.

O artigo terceiro da Lei № 8.069 visa assegurar a eles, nos trâmites legais, todas as oportunidades e facilidades capazes de lhes facultar o desenvolvimento físico, mental, moral, espiritual e social, em plenas condições de liberdade e de dignidade. A mesma legislação é fulgente ao defender os direitos da criança à proteção social, listando no seu artigo terceiro os direitos das pessoas nessa faixa etária.

Com base nessas informações é possível afirmar que existe uma grande preocupação com a violência na infância e na adolescência, tendo em vista que é nesse período de grande fragilidade que ocorre o maior desenvolvimento humano.

A violação dos direitos da criança e sua exposição a diversas formas de violência é um grave problema enfrentado historicamente a nível mundial. Nunes e Sales (2015) concebem violência enquanto uso da força física ou do poder, seja contra outra pessoa, um grupo, uma comunidade ou até a si próprio, possível de resultar em lesão, morte, danos psicológicos e/ou físicos, conflito de desenvolvimento ou privação de direitos. Assim sendo a violência pode trazer danos tanto físicos quanto psicológicos.

Ao definir a violência Balbinotti (2008) recorre à Guerra (2004) para a qual a violência obedece ao ato ou efeito de violentar, com emprego da força física contra alguém ou algo, ou pela intimidação moral. Assim a violência infantil está nas atitudes e/ou omissões advindas de pessoas do ambiente de convívio cotidiano da criança, a qual pode ser praticada pelos pais, parentes e/ou responsáveis pelas crianças e adolescentes e lhes causar dano físico, sexual e/ou psicológico. Isso implica a transgressão do poder/dever de proteção do adulto paralela à negação do direito que crianças e adolescentes, cuja condição peculiar de desenvolvimento requer atenção especial.

Acredita-se que as raízes da violência infantil estão no histórico da concepção de infância, tendo em vista a existência de registros que evidenciam essa prática ao longo da história da humanidade em distintos contextos, embora com um olhar diferenciado pela sociedade. Estudos revelam que na idade média as crianças eram educadas através de costumes religiosos, cuja aplicação de uma educação severa e torturante era permeada de castigos, punições dentre outros, de acordo com Machado e Sanches (2014). Nesse contexto as atitudes violentas dos adultos visavam moldar as crianças em conformidade com os padrões sociais da época.

Alberto et al. (2008) também citam o cenário nacional no qual existem formas diferenciadas da sociedade compreender e tratar as fases da infância e da adolescência, dependendo das categorias sociais de pertencimento. Existe assim uma forte desigualdade

Rev. Psicol Saúde e Debate. Fev., 2018:4(1):61-84. 
social na relação da infância e da adolescência, as crianças e adolescentes advindas das classes dominantes vivenciam um desenvolvimento prolongado, enquanto as oriundas das classes dominadas, de baixo poder aquisitivo, têm sua infância e adolescência abreviadas.

Machado e Sanches (2014) declaram que apenas a partir do século XIX se iniciaram os interesses acadêmicos nos campos, afetivos, econômicos e existências das crianças, o qual evoluiu progressivamente culminando na criação Estatuto da Criança e do AdolescenteECA, em 1990, através da Lei 8.069. Tal legislação visou proteger as crianças e os adolescentes de todas as formas de violência na busca de sua dignidade humana. No seu artigo $4^{\circ}$ é proposta a efetivação dos direitos à vida, à saúde, à alimentação, à educação, ao esporte, à profissionalização, à cultura, à dignidade e ao respeito, dentre outros, enquanto dever da família, da comunidade, da sociedade em geral e do poder público os quais devem assegurá-los com absoluta prioridade.

O ECA consiste na maior tentativa governamental de evitar e/ou erradicar os atos de violência infantil que ocasionam marcas físicas, traumas emocionais e baixa espiritualidade, decorrentes de todo e qualquer ato violento, desencadeados pelos mais diversos motivos. Porém, como declaram Machado e Sanches (2014), apesar dos avanços legais e da ampla divulgação dos direitos da criança e do adolescente, o combate da violência não está sendo eficaz.

Nunes e Sales (2015) criticam a violência, sobretudo aquela cometida contra a criança, cujas condições peculiares de desenvolvimento as colocam em extrema dependência de pais, familiares, cuidadores, do poder público e da sociedade. Ao analisarem as estatísticas relativas os autores salientam que houve nos últimos tempos um acentuado avanço da violência infantil. São diversas as formas de violência encontradas na sociedade. Faleiros e Faleiros (2007) afirmam que a violência contra crianças e adolescentes ocorre de várias maneiras, por diferentes autores e em distintos lugares. Eles citam como as classificações mais usuais das formas de violência: violência física, psicológica e sexual.

Um dos principais meios de controle dos índices de violência infantil é o Sistema de Informação de Agravos de Notificação (SINAN) órgão responsável por notificar nacionalmente os atendimentos relativos. Foram registrados 39.281 atendimentos na faixa de etária de $1 \mathrm{a}$ 19 anos idade, o que representa $40 \%$ do total de 98.115 atendimentos pelo órgão computado no ano de 2011.

O aumento no número de casos de violência infantil, segundo os dados epidemiológicos mundiais e brasileiros, citados por Nunes e Sales (2015), evidencia uma demanda por ações eficazes de controle e de prevenção, por parte dos setores sociais envolvidos, dos profissionais de saúde e dos conselhos tutelares, dentre outros. O combate à

Rev. Psicol Saúde e Debate. Fev., 2018:4(1):61-84. 
violência infantil só terá eficiência quando for encarado como um problema coletivo e que toda a sociedade precisa ser envolvida no processo preventivo e também na correção dos desvios encontrados.

Dentre os profissionais que podem contribuir na prevenção da violência infantil os que compõem a área da psicologia se evidenciam, tendo em vista sua intrínseca relação com a compreensão do ser humano. Abordando a importância do Psicólogo na defesa da criança Alberto et al. (2008) propõem a concepção da proteção integral, na qual a atuação ocorra dentro de uma rede de complementaridade técnica junto aos demais profissionais da saúde, e o desenvolvimento social e das famílias.

Analisando as concepções expostas pelos autores estudados torna-se compreensível que o psicólogo representa um mediador dos direitos da criança, um viabilizador de direitos, e para essa mediação ele precisa ter conhecimento profundo da legislação, competências e a autonomia política administrativa. Tal como afirma Balbinotti (2008) ao psicólogo é atribuída a participação e o controle, o que requer um arcabouço teóricotécnico-operativo que aponta ao fortalecimento de práticas e espaços de debate. Logo é concebível que a criança precisa de um trabalho sério, engajado e de ampla coletividade entre as políticas públicas e diversos profissionais para que seja protegida da violência a qual tem sido historicamente submetida.

O presente trabalho tem como objetivo analisar publicações relativas à violência infantil e apontar possibilidades de atuação do profissional da Psicologia no trato com as questões nesse contexto. Embasada na revisão literária de artigos acadêmicos publicados nos últimos dez anos é almejado confrontar concepções de renomados autores acerca da violência infantil, bem como levantar um breve histórico da concepção de infância, abordando ainda a relevância do trabalho preventivo e de amenização dos danos pela ação do psicólogo.

A pesquisa de cunho bibliográfico visou compilar informações básicas acerca do tema violência infantil e associar a relevância do trabalho dos profissionais da psicologia na amenização dos impactos advindo dessa realidade. Nos dizeres de Severino (2007) a pesquisa bibliográfica se realiza a partir de registros encontrados nas pesquisas afins anteriores estudo, documentados e impressos disponibilizados virtualmente, tais como os livros e artigos. Nela são utilizados dados teóricos já trabalhados e devidamente registrados. Os textos, como afirma o autor citado anteriormente, se fazem fontes dos temas a serem pesquisados, e o pesquisador se embasa nas contribuições dos autores dos estudos neles constantes.

Na pesquisa qualitativa, como salienta Severino (2007), são utilizados os dados ou as categorias teóricas anteriormente pesquisados e devidamente registrados, assim os textos

Rev. Psicol Saúde e Debate. Fev., 2018:4(1):61-84. 
correspondem às fontes dos temas em estudo, pois o pesquisador se embasa nas contribuições dos autores dos estudos analíticos constantes dos textos.

Esse estudo se pautou em variados documentos científicos publicados nos últimos dez anos, no período compreendido entre 2006 a 2016. Houve a definição de termos relativos à violência infantil, a caracterização dessa realidade e o apontamento de possibilidades de atuação do profissional da área da psicologia no auxílio à criança vitimada.

\section{MARCO CONCEITUAL}

Ao discorrer sobre a violência infantil é fundamental considerar essa questão enquanto um problema amplo e apontar algumas das vertentes mais comuns encontradas nas pesquisas relativas. Embora a sociedade moderna já esteja vivendo em pleno período de globalização e de ampla expansão de informações, a violência infantil é um fato concreto e abrangente. Ela atinge todas as classes sociais, variando conforme as questões socioculturais e ambientais, mas persistindo em inúmeros espaços do planeta.

Nunes e Sales (2015) definem a violência infantil enquanto uso da força física ou do poder, real ou em ameaça, contra si próprio, contra outra pessoa, ou contra um grupo ou uma comunidade, que resulte ou possa resultar em lesão, morte, dano psicológico, deficiência de desenvolvimento ou privação.

A Organização Mundial da Saúde (OMS), como afirmam Dahlberg e Krug (2007), define a violência enquanto o uso de força física ou poder, em ameaça ou na prática, contra si próprio, contra outra pessoa ou contra um grupo ou comunidade que proceda ou possa proceder em sofrimento, morte, dano psicológico, desenvolvimento prejudicado ou privação. Tal definição associa a intencionalidade à realização do ato, independentemente do resultado causado.

Dahlberg e Krug (2007) apontam as três amplas categorias propostas pela OMS ao classificar a violência quanto a tipologia, conforme as características dos que comentem ato violento: a violência autodirigida (comportamento suicida e agressão auto-infligida); a violência interpessoal (violência de família e de parceiros íntimos ou na comunidade, entre indivíduos sem relação pessoal); e a violência coletiva (tipo que sugere possíveis motivos para a violência cometida por grandes grupos ou por países, podendo ser social, política e econômica).

A OMS classifica a natureza dos atos violentos em quatro grupos, assim a violência pode ser física, sexual, psicológica e/ou relacionada à privação ou ao abandono. Dahlberg e Krug (2007) esclarecem que, em muitos casos há a associação de vários desses grupos de

Rev. Psicol Saúde e Debate. Fev., 2018:4(1):61-84. 
violência, citando o como exemplo, quando a violência contra crianças é praticada nos lares ela pode conter abuso físico, sexual e psicológico, bem como o abandono.

De acordo com Balbinotti (2008) a questão mais relevante no trato com a violência infantil está na proteção da vítima. A seu ver são várias as áreas profissionais e os diferentes órgãos que são envolvidos nos casos denunciados, tais como o Conselho Tutelar, o Ministério Público, a rede de saúde assistencial, entre outros. Porém o foco principal dos procedimentos deveria ser, primeiramente, proteger a vítima e, depois, buscar mecanismos de responsabilização do abusador.

Os danos psicológicos advindos da exposição à violência podem se converterem em potenciais danificadores da estrutura de desenvolvimento integral da criança e do adolescente. Tomando como parâmetro essa percepção é relevante considerar os conhecimentos advindos da Psicologia, pelo conhecimento do ser humano a ela vinculado.

\section{GÊNESE DA VIOLÊNCIA INFANTIL E POLÍTICAS PÚBLICAS RELATIVAS}

A história da violência infantil tem sua gênese na história da humanidade e varia conforme o contexto e a cultura de cada grupo social. Segundo Machado e Sanches (2014) ela acompanha a história da humanidade desde seus primórdios. Eles citam que na Bíblia Sagrada há relatos do livro do Êxodo da morte de meninos recém-nascidos sob ordem do Faraó, devido ao nascimento de Moisés e a perseguição ao menino Jesus que gerou a matança de crianças menores de dois anos, ordenada por Herodes. Ao discorrerem sobre a educação das crianças na Idade Média pelos religiosos os autores supracitados adverte que esse processo severo e torturante era justificado nos hábitos de castigos, punição física, espancamento com chicote, ferros e pau em nome da moldagem das crianças aos desejos dos adultos.

Discorrendo sobre o histórico da violência infantil especificamente no Brasil Alberto et al. (2008) declaram que desde a vinda dos exploradores portugueses até a atualidade a criança e o adolescente vivenciam experiências de violência, exclusão, abuso sexual e maus tratos. Tal processo de violação começou em Portugal, pelo recrutamento de crianças e adolescentes pobres, entre 9 e 16 anos (advindas de orfanatos e/ou rapto de crianças e adolescentes judias) para fazerem parte da tripulação das naus transoceânicas. No período da escravidão as crianças filhas de negros já adentravam à condição de escravo aproximadamente aos sete anos de idade, sendo incorporadas aos comportamentos sociais ficando já suscetível aos castigos corporais e às humilhações.

Rev. Psicol Saúde e Debate. Fev., 2018:4(1):61-84. 
Conforme os autores supracitados declaram que, no final do século XIX e no início do século $X X$, o processo de industrialização, incorporado à imigração, dinamizou as cidades e acentuou as diferenças entre as classes sociais. As crianças das classes sociais mais baixas voltaram a ser vítimas e as políticas públicas buscavam a disciplinarização das crianças e jovens pela pedagogia do trabalho.

A partir da Lei do Ventre Livre, com maior elevação no final dos anos 70 e início dos anos 80 , segundo Alberto et al. (2008) acentua-se o número de crianças e adolescentes de ambos os sexos e de diferentes faixas etárias que passam a maior parte de seu dia nas ruas, exercendo trabalho formal ou informal, bem como atos ilícitos, para auxiliar no sustento familiar. Esse é um fenômeno psicossocial diz respeito ao desenvolvimento de sujeitos que deveriam ter na família as bases psíquicas e sociais para se estruturarem como adultos, serem humanos e cidadãos.

Para Machado e Sanches (2014), no final do século XIX e início do século XX começou-se a visualizar os direitos infantis e a valorização de suas peculiaridades, surgindo o interesse em investir nos filhos no campo afetivo, econômico, educativo e existencial, e em auxiliar as crianças oriundas de famílias pobres. Os autores se embasam em Felizardo e Ribeiro (2004) ao afirmarem que somente no final do século XX, que a medicina, a psicologia, a pedagogia e o direito começam a pensar em um novo conceito de atendimento às crianças quando surgiu o Estatuto da Criança e do Adolescente.

Classificando a violência infantil conforme os tipos Ewerton et al. (2013) descrevem sobre a violência física, a negligência, a violência psicológica e/ou a sexual. Na violência física há o uso intencional da força física, praticado por pais, responsáveis, familiares ou pessoas próximas da criança e adolescente, como o objetivo de ferir, lesar ou destruir a vítima, deixando ou não marcas corporais evidentes. Já a negligência é definida enquanto omissão de cuidados básicos (privação de medicamentos; falta de atendimento aos cuidados necessários, ausência de proteção).

Relativo à violência psicológica, Ewerton et al. (2013) as integram nas várias formas de rejeição, depreciação, discriminação, desrespeito, cobranças exageradas, punições humilhantes e/ou utilização da criança ou do adolescente para atender às necessidades psíquicas dos adultos. Já a violência sexual se caracteriza em atos sexuais nos quais o agressor está em estágio de desenvolvimento psicossexual mais avançado que a vítima e visa a própria satisfação. Nesses casos, conforme tais autores, o violentador intenciona estimular sexualmente a vítima ou utilizá-la para obter satisfação sexual, impondo à criança ou ao adolescente pela violência física, ameaças ou indução de sua vontade.

Rev. Psicol Saúde e Debate. Fev., 2018:4(1):61-84. 
Ao abordar os tipos de violência predominantes contra crianças Nunes e Sales (2015) veem na negligência uma das formas mais frequentes. Esse tipo é difícil de definir, pois envolve aspectos culturais, sociais e econômicos de cada família ou grupo social. A privação materna é, para os autores, potencial estressor que afeta diretamente o desenvolvimento infantil, pois os indivíduos vítimas de negligência, ou doutros tipos de violência na primeira década de vida, de modo geral, apresentam maiores tendências de desvios de conduta e/ou transgressões das regras sociais.

No cenário nacional entre as crianças pequenas os índices de violência física e psicológica são evidenciados se comparadas às crianças maiores. Ao discutir a predominância da violência infantil na atualidade Nunes e Sales (2015) afirmam que as crianças menores são as vítimas mais comuns. Comumente quanto menor a idade, maior a vulnerabilidade e maior o risco de violência.

Relativo à adolescência um dos problemas mais graves está nas condições de vulnerabilidade encontrada nas ruas, sobretudo na exposição à violência sexual. Para Alberto et al. (2008) essa forma de violência se evidencia sob várias formas, indo do abuso familiar a comercialização na indústria pornográfica.

O avanço das políticas públicas ocorre, sobretudo com a criação do Estatuto da Criança e do Adolescente, através da Lei 8.069, que visou garantir às crianças e ao adolescente, a promoção da saúde e a prevenção de agravos, e torna obrigatória a identificação e a denúncia de violência. Ressaltam os autores que a criação do ECA forneceu ao Estado instrumentos legais para a proteção nas situações de violência contra as crianças e os adolescentes, ao tornar obrigatória a sua notificação até mesmo nos casos de suspeita.

No Brasil a situação da violência contra crianças e adolescentes ganhou visibilidade graças também as intervenções estrangeiras, dentre as quais Alberto et al. (2008) destacam a realização da comissão Parlamentar de Inquérito (CPI) da Prostituição Infanto-Juvenil e de congressos temáticos, os quais alavancaram grandes progressos conceituais de base para a elaboração de estratégias preventivas e/ou coercitivas a níveis internacionais.

Um dos tipos de violência contra crianças e adolescentes que alcançam muita visibilidade se refere justamente à violência sexual. Abordando essa questão Faleiros e Faleiros (2007) a diferem em abuso sexual (em intra e extrafamiliar) e exploração sexual comercial (prostituição, pornografia, turismo sexual e tráfico de pessoas para fins sexuais). Tais autores advertem ainda que essa classificação, se rigorosamente analisada, pode revelar imprecisões e lacunas.

De acordo com Nunes e Sales (2015) na violência sexual se expressa o poder do adulto na satisfação de seus desejos contra a criança indefesa, pois a relação sexualmente 
abusiva consiste na imposição do poder do adulto que vitima sob a criança que é vitimizada. Dentre as diversas formas de violência infantil a violência sexual tem recebido amplo destaque, tanto por sua numerosidade o quanto por sua abrangência a vida da vítima. Segundo a concepção desses autores é evidente a predominância desse tipo de violência, embora não sejam encontrados estudos decisivos nesse contexto.

Bonvicini e Silva (2015) consideram favoráveis ao desenvolvimento da saúde o fortalecimento das capacidades dos indivíduos e suas comunidades, o estimulo à a capacitação da comunidade para atuar na melhoria da sua qualidade de vida e saúde e a busca por uma ampla participação no controle deste processo. E ressaltam como uma das responsabilidades dos indivíduos e das comunidades o investimento na sua própria saúde. Portanto, sendo a violência uma potente causadora de problemas de saúde física e mental, é imprescindível que se busque a sua erradicação para que as crianças e adolescentes possam se desenvolver em ambientes saudáveis e livres de problemas afins.

Com base nesses pressupostos é concebível que a questão da violência infantil advém de longa história, está entranhada na sociedade em geral, inclusive no seio de muitas famílias e precisa da mobilização integral da sociedade para ser superada. Logo as formas de violência variam muito, mas em todas elas se retrata o descaso com os direitos da criança e do adolescente enquanto ser em formação e que requer cuidados específicos para se desenvolverem integralmente.

\section{FATORES DE RISCO PARA A VIOLÊNCIA INFANTIL E SUAS CONSEQUÊNCIAS}

São diversos os fatores que influenciam a ocorrência da violência infantil, pois ela não se restringe a ambientes exclusivos das classes pobres, abrangendo todas as classes sociais e em inúmeros contextos, se expressando de formas distintas em todos os grupos.

A concepção de violência como problema que atinge a todas as classes sociais é exemplificada por Machado e Sanches (2014) que apontam fatores como o uso excessivo de drogas e a ausência de valores enquanto potenciais elevadores dos índices de violência em todas as classes sociais, salientando ainda que nos ambientes de maior pobreza ela se faz mais comum. A falta de estrutura social também se faz um agravante na exposição da criança e do adolescente a violência. Sobre a temática Machado e Sanches (2014) citam o UNICEF (1998), o qual aponta que muitas crianças e adolescente são vítimas e alvos das desigualdades da estrutura social, como: desregulamentação dos direitos à educação, moradia, saúde e também são vitimizada pela violência física; psicológica e/ou sexual.

Rev. Psicol Saúde e Debate. Fev., 2018:4(1):61-84. 
Na perspectiva do apontamento dos fatores de risco é perceptível a existência de um conjunto deles, os quais se constituem meios de ampliação da ocorrência de situações de violência contra a criança. Relativo às consequências da violência Ewerton et al. (2013) declaram que a violência pode causar marcas profundas e até mesmo óbitos. Logo são muitos os efeitos desencadeantes pela violência familiar.

Discutindo os efeitos da violência Machado e Sanches (2014) diferem os principais distúrbios à violência infantil associados, denominando-os em danos imediatos como os pesadelos repetitivos, ansiedade, raiva, culpa vergonha; quadros fóbico-ansiosos e depressivos agudos, queixas psicossomáticas, isolamento social entre outros. Além desses tem-se os danos tardios percebidos no aumento significativo na incidência de transtornos psiquiátricos como a dissociação afetiva, ideação suicida e fobias mais agudas, ansiedade, medo, depressão.

As reações variam de situações e também de indivíduos vitimados, podendo haver amplas variações. O que é certo é a existência das manifestações psicológicas relativas. Referindo-se especificamente a violência sexual Balbinotti (2008) declara serem inúmeras e variadas as consequências do abuso sexual. A autora evidencia que tais consequências alteram caso a caso, dependendo de variados fatores, tais como a idade da criança na época do abuso sexual, do elo de ligação desta com o abusador, do seu ambiente familiar, do impacto que o abuso terá após a sua revelação, da reação dos conhecidos e também das decisões sociais, médicas e judiciárias que intervirão no caso.

Dentre os sintomas e manifestações mais comuns Balbinotti (2008) refere-se à Mari Lucrécia Zavaschi (1991) ao citar desde a automutilação aos transtornos psiquiátricos, ou até a tentativa de suicídio e/ou a adição a drogas. E lista como sintomas mais comuns das crianças a depressão, o isolacionismo, despersonalização, isolamento afetivo, hipocondria, a timidez, os distúrbios de conduta, as síndromes dissociativas, os transtornos severos de personalidade e/ou de estresse pós-traumático.

Geralmente os abusos sexuais são somáticos e causam danos diversos. Nunes e Sales (2015) atentam para a gravidade dos danos advindos da violência sexual, evidenciando que as crianças não estão preparadas física, cognitiva, emocional ou socialmente para encarar as situações relativas, devido à imaturidade.

Balbinotti (2008) concebe que as crianças abusadas sexualmente e desamparadas reagem das mais distintas formas. Ela cita a dissociação enquanto uma das reações muito comuns, no intuito subconsciente de fuga à situação intolerável. Assim sendo é explicitado que as crianças tendem a fingir que não são elas que estão sofrendo a violência, esse mecanismo a auxilia a sobreviver a situações de exploração que podem perdurar por longos

Rev. Psicol Saúde e Debate. Fev., 2018:4(1):61-84. 
anos, e gerar sequelas ocasionadoras de problemas emocionais na fase adulta. Balbinotti (2008) destaca que o abuso sexual da criança pode causar uma síndrome do segredo, o que frequentemente, gera distúrbios de personalidade e traumas permanentes associados ao terror sofrido na infância.

Abordando especificamente a síndrome do segredo Nascimento (2009) ressalta essa como a característica mais marcante da violência intrafamiliar, pois geralmente a criança não revela o abuso, é constantemente ameaçada e até mesmo subornada com presentes para que não o revele. Conforme a autora as consequências emocionais para a vítima podem ser desastrosas, a situação a leva a sentir-se insegura, triste e até mesmo culpada.

Nascimento (2009) salienta que a pressão psicológica por parte da família e do próprio agressor concretiza na vítima uma confusão mental, distorcendo a realidade e crendo na própria culpa. Fatalmente, como declara a autora, a maioria das vítimas de abuso sexual se depara com problemas afetivos, interpessoais e sexuais, e criam a concepção de que consentiram para que o fato ocorresse, desconsiderando as ameaças, a força e as pressões sofridas. Dentre as preocupações encontradas nesse contexto a autora cita o medo da desestruturação familiar se evidencia, independente da classe social essa questão é muito comum.

Relativo a essa questão Balbinotti (2008) cita Tilman Furniss o qual enumera diversos fatores externos e internos promovem a síndrome do segredo: a falta de evidências médicas e de elementos que comprovem o abuso sexual infantil; a indigência de acusação verbal por parte da própria criança; a falta de credibilidade em relação à vitima. Também são mencionados fatores como as consequências da revelação, as ameaças físicas e psicológicas, a distorção da realidade, o medo de punição, o sentimento de culpa vivido pela criança, a negação e a dissociação.

Na concepção de Nascimento (2009), em geral, a criança se torna desconfiada em relação a todos que a rodeiam, o que gera impasse aos operadores do direito no buscam devidos as evidências para confirmarem o abuso sofrido. Logo cabe aos profissionais que atuam perante esta situação, somar esforços para levar a vítima a expor os fatos de modo tranquilo, confortável e seguro, adequado às suas fragilidades e respeitando suas condições. A autora considera fundamental que os profissionais que lidam com as crianças e os adolescentes abusadas sexualmente lhes incentivem na recuperação da autoestima e na remoção da responsabilidade destes sob o caso, pelo esclarecimento relativo aos fatos ocorrido.

Discutindo especificamente a influência da violência no âmbito da saúde física e mental das pessoas Bonvicini e Silva (2015) veem no conceito de promoção da saúde o 
entendimento que esta se vincula à qualidade de vida; as boas condições de formação integral ao longo de toda a vida, ao ambiente físico limpo e ao apoio social para famílias e indivíduos. Assim os adequados cuidados de saúde se voltam ao coletivo e ao ambiente, compreendidos num sentido amplo, que abrangem fatores físico, social, político, econômico e cultural. Para tais autores a saúde integral é indissociável das políticas públicas que se fortalecem nas estratégias de promoção de saúde. Logo, oferecer as crianças e adolescentes condições propícias à sua saúde requer também o convívio em ambientes não violentos.

Outra questão relevante acerca do convívio com a violência infantil está na ampliação das possibilidades de envolvimento dessas vitima com o mundo das drogas. Segundo Soares e Mendes (2017) as crianças e adolescente que convivem em ambientes conflitantes e que sofrem agreções físicas, emocionais e/ou sociais na infância estão mais propensos a fazer o uso de drogas e a desenvolverem comportamentos agressivos.

Tomando como parâmetros as informações abordadas podem se afirmar que a violência infantil ocasiona inúmeros problemas de ordem física e psicológica, portanto a proteção da criança e do adolescente é imprescindível na prevenção desses transtornos.

\section{A ATUAÇÃO DO PSICÓLOGO E O MANEJO INTERSETORIAL}

No contexto da proteção da criança contra a violência e à amenização dos danos por ela causados, os profissionais da psicologia se ressaltam, tendo em vista seu papel protetivo e o potencial para auxiliar na amenização dos danos psicológicos causados as crianças e adolescentes vitimados.

Abordando as ações devidas pelo psicólogo no trato com crianças vitimadas pela violência infantil Balbinotti (2008) salienta a relevância de se ouvir a criança com cautela e profissionalismo, para evitar novos danos psicológicos. As formas de proceder a oitiva da criança sexualmente abusada carecem de lhes resguardar de novos danos psicológicos, garantindo simultaneamente ao acusado o direito ao devido e justo processo legal. Balbinotti (2008) lembra ainda a existência de uma proposta aprovada pela Câmara de Deputados sobre alteração legal prevendo a realização de um laudo psicossocial, pela equipe interprofissional,

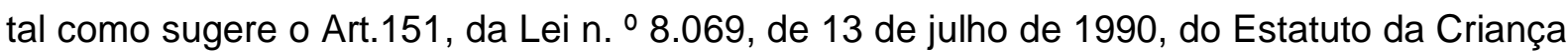
e do Adolescente.

O trabalho em parceria e abrangente também é defendido por Nunes e Sales (2015) para os quais os profissionais de saúde, precisam traçar metas voltadas à intervenção segura e eficaz. Sobre o trabalho em equipe o Conselho Nacional dos Direitos da criança e do Adolescente (CONANDA) também apresenta parecer favorável. Essa concepção é exposta

Rev. Psicol Saúde e Debate. Fev., 2018:4(1):61-84. 
pelo Conselho Federal de Psicologia (2003) e citada por Alberto et al. (2008) que expõem a relevância da união de forças ao integral desenvolvimento das medidas sociais de promoção da não violência.

Também acerca do papel do psicólogo nas políticas sociais Alberto et al (2008) citam Bock (2003) que vê nessa profissão a necessidade de um amplo compromisso social, voltado à construção de teorias e práticas destinadas à transformação social sobretudo na proteção das camadas populares. Eles defendem a atuação embasada na numa psicologia dialética que olhe e atue, a partir do contexto, na participação política e nos espaços de confronto em defesa dos direitos dos cidadãos. E salientam como fundamental que o profissional de Psicologia atuante em entidades que atendem crianças e adolescentes em situação de risco entenda e trabalhe sob a perspectiva de que a criança e o adolescente são sujeitos que precisam das políticas sociais básicas a fim de ter garantida a proteção integral, fundamental para o seu desenvolvimento.

Relativo ao tema Soares e Mendes (2017) salientam a relevância das medidas protetivas, enfatizando a proteção enquanto caminho mais eficaz, seguro e acessível ao alcance das condições básicas de desenvolvimento da pessoa em fase de formação. Para tais autores um desenvolvimento social e afetuoso equilibrado reduz ou paralisa o conflito do risco. Assim é função essencial da sociedade a proteção de crianças e adolescentes contra o envolvimento com drogas e outros procedimentos de risco. Dentre as ações sugeridas para alargar os fatores de proteção os autores citam a saudável convivência no seio familiar.

Alberto et al. (2008) citam que ainda existe a reprodução de práticas antiquadas pelo psicólogo que embasam sua prática na velha cultura do disciplinamento de jovens pobres, manifesta na profissionalização, no acompanhamento de medidas ou no planejamento familiar, distante da necessária educação sexual. Essa realidade revela que a atuação do psicólogo nas entidades de atendimento a crianças e adolescentes em situação de risco se distancia da almejada figura do viabilizador de direitos e promotor de espaço político, público e coletivo, atuante dentro de um sistema de rede e de complementaridade técnica. Percebese que, na prática, as instituições não atuam em rede, e o psicólogo atua, prioritariamente, a partir do seu conhecimento específico, desconsiderando a criança e o adolescente como detentores de direitos e protagonistas de sua história.

$\mathrm{Na}$ perspectiva de um trabalho abrangente Bagagi e Paiva (2012) ressaltam a perceptível necessidade de elaboração de propostas voltadas à facilitação do trabalho dos profissionais de saúde no enfrentamento da violência infanto - juvenil. Dentre as ações sugeridas estão o oferecimento de cursos de qualificação para atuação do profissional, a

Rev. Psicol Saúde e Debate. Fev., 2018:4(1):61-84. 
execução de palestras educativas para os familiares nos setores de atendimento ás crianças e adolescentes e a elaboração de protocolos de atendimentos para as vítimas de violência.

Bagagi e Paiva (2012) salientam também a importância do aperfeiçoamento do trabalho coletivo entre os órgãos responsáveis pelo atendimento às crianças e adolescentes vitimadas pela violência. E destacam a relevância das parcerias entre os hospitais, as delegacias de policia, os conselhos tutelares, os centros de referência especializados da assistência social (CREAS) e o Ministério Público, no intuito de garantir o princípio constitucional da preferência absoluta da proteção integral das vitimas.

Ao discutir especificamente os casos de violência sexual Nascimento (2009) enaltece o papel do psicólogo, declarando que o trabalho em conjunto com as autoridades é fundamental. Segundo a autora os psicólogos estão capacitados para compreender a mente e os processos mentais do comportamento humano, assim representam um grande passo na resolução de casos controvertidos como a violência sexual. Nascimento (2009) adverte que magistrados e psicólogos devem buscar um objetivo comum, oferecendo espaço para que a vítima exponha o ocorrido e extrair dela o essencial, contribuindo para que prevaleça a justiça, o acolhimento e a proteção da vitima.

A atuação do psicólogo, segundo Alberto et al. (2008) se dá principalmente no modelo clínico e individual, excluindo ações no âmbito do contexto e centrando sua intervenção no indivíduo. Do ponto de vista dos profissionais, várias são as dificuldades destacadas no seu trabalho, predominando as de ordem econômica e estrutural e a descontinuidade da clientela. Sabe-se que existe a expectativa de muitos profissionais por um setting concebido dentro do modelo clínico e uma cobrança de enquadre do cliente. Esse modelo clínico, para Alberto et al. (2008) é individualizante e impede o profissional de cumprir seu papel de mobilizador e promotor da defesa dos direitos das crianças e adolescentes, na busca da prevenção, da inclusão social e do protagonismo juvenil.

Relativo ao papel do psicólogo Froner e Ramires (2008) se embasam em Junqueira (2002) o qual salienta a relevância da brincadeira livre enquanto uma linguagem importante e usual para expressão da criança, que deve ser valorizada na sua escuta para a superação e elaboração da situação traumática. Conforme os autores a experiência da criança se evidencia com maior facilidade, sem indução alguma. O profissional deve considerar a experiência vivenciada pela criança e a tensão psíquica a ela vinculada para promover intervenções que permitam uma elaboração psíquica do seu estado emocional.

A atitude do profissional frente aos fatos apresentados, segundo Advertem Froner e Ramires (2008), não pode ser julgadora ou punitiva, é fundamental o estabelecimento de uma relação de confiança, a qual alicerçará o acompanhamento subsequente. Nessa perspectiva

Rev. Psicol Saúde e Debate. Fev., 2018:4(1):61-84. 
a escuta é defendida sempre em benefício da criança, a qual precisa sentir-se respeitada incondicionalmente, devendo sua maneira de se expressar e até mesmo o seu silêncio serem compreendidos. Em síntese, as autoras salientam a relevância de que profissionais que escutam as crianças abusadas priorizem seu acolhimento.

A superação da violência infantil depende de ações articuladas, eficazes e bem norteadas no sentido de valorização e do resgate do ser humano atingido por ela. Retomando as concepções expostas por Klippel e Camargo (2015) é fundamental que pesquisadores e trabalhadores sociais se envolvam de modo compromissado com a vida de seus protegidos. Assim sendo não basta a construção de práticas comunitárias voltadas às mudanças e melhorias na vida, a autora vê como imprescindível auxiliá-las na compreensão da realidade pela superação das condições de opressão e exclusão cotidiana de tais indivíduos.

Quanto ao trabalho em formas de redes Sonego e Kolody, (2012) também expressam suas posições favoráveis, concebendo como imprescindível à atenção a crianças e adolescentes, a criação de estratégias de enfrentamento do fenômeno, partindo da consideração de suas particularidades de cada realidade. As autoras valorizam também a articulação por meio das redes sociais, vendo na construção de tais redes de atendimento uma potente e necessária alternativa de enfrentamento das manifestações da exclusão social.

Guerra (2008) também ressalta a necessidade da luta coletiva na prevenção do fenômeno. Ela divide a prevenção em primária (estratégias dirigidas ao conjunto da população para reduzir a incidência de ocorrência) secundária (identificação precoce da 'população de risco') e terciária (voltada aos que já são agressores ou vítimas visando reduzir as consequências adversas do fenômeno e/ou evitar que o indivíduo sofra o processo de incapacidade permanente).

Ainda conforme a autora supracitada é necessária a criação de redes de potencialização da prevenção, vendo nessa forma de trabalho um potencial meio de enfatizar a atuação integrada e intersetorial. Tal trabalho deve envolver todas as organizações vinculadas às crianças e adolescentes, suas respectivas famílias e os próprios interessados, operando virtualmente e também, de forma abrangente, de modo presencial, pois na construção desse um projeto coletivo um dos requisitos essenciais é o estar fisicamente juntos.

Em consonância com as concepções apresentadas Bagagi e Paiva (2012) ressalvam a importância dos profissionais da saúde nos três níveis de atenção à saúde: primário, secundário e terciário. No setor primário que visa à prevenção e a redução do número de casos de violência, eles propõem o desenvolvimento de ações durante o período do pré- natal, como exemplo, a promoção do alojamento conjunto com a mãe e o recém nascido, pelo 
fortalecimento do vínculo e a afeição familiar. No setor secundário sugerem que a atuação dos profissionais se volte à identificação de famílias mais vulneráveis, como exemplo os pais usuários de drogas, cabe também aos profissionais a avaliação das consultas pré-natais e o encaminhando e orientação relativos ao tratamento adequado.

Quanto ao setor terciário, sobre a circunstância já ocorrida, Bagagi e Paiva (2012) enfatizam o trabalho de prevenção da reincidência da violência. Logo, se a situação de violência é identificada a atuação profissional precisa superar a punição relativa à família e a criança. Cabe à equipe oferecer estratégias e orientações para a resolução do problema e comunicar às autoridades competentes.

Discutindo a relevância das ações preventivas e das intervenções inerentes a violência infantil, Klippel e Camargo (2015) concebem como essencial a análise contextualizada de vários aspectos que se imbricam para o vislumbre de caminhos teóricopráticos mais coerentes. Vendo o decréscimo dos valores coletivos e/ou comunitários enquanto uma das características mais evidenciada nas sociedades globalizadas a autora compreende a necessidade da superação do individualismo.

A implementação de programas e ações coletivas podem contribuir significativamente com propostas de emancipação e superação das condições de exploração e opressão. Na concepção de Klippel e Camargo (2015) a investigação pode conduzir a ações implicadas na mesma direção do compromisso social caso a intervenção contribua para a produção de conhecimentos, porém ambos precisam ser conduzidos de modo compromissado e responsável. Na perspectiva de proteger a criança e/ou de reduzir os danos causados pela violência infantil é fundamental que profissionais de variados setores sejam envolvidos.

Para Alberto et al. (2008) as políticas sociais básicas são imprescindíveis para assegurar a proteção integral da criança. Para o êxito é fundamental que os conselhos de direitos operem de modo articulado (contemplando a promoção, a defesa e o controle social) buscando garantir os direitos e enfrentar as violações sofridas por crianças e adolescentes, designadamente aquelas em situações de risco pessoal e social.

Os autores supracitados defendem a relevância da promoção e da realização dos direitos infantis pelos setores públicos (gestores da saúde, educação, assistência social), evidenciando o papel dos conselhos de Direitos da criança e do Adolescente e dos conselhos Setoriais (assistência social e educação). Relativo à defesa esclarecem a importância da responsabilização no caso de omissão, falta ou oferta irregular dos Direitos por parte da família, do Estado ou da sociedade, bem como do Ministério Público e do Trabalho, do

Rev. Psicol Saúde e Debate. Fev., 2018:4(1):61-84. 
conselho Tutelar, do Judiciário, da Defensoria Pública e dos centros de Defesa de Direitos Humanos. O controle social visa acompanhar e fiscalizar o cumprimento desses direitos.

Relativo aos avanços legais, no contexto brasileiro, Klippel e Camargo (2015) ressaltam a relevância das leis para que haja a proteção da criança e a veiculação dos textos afins. A autora cita o Estatuto da Criança e do Adolescente e as Orientações Técnicas de Serviços de Acolhimento para Crianças e Adolescentes, veiculada pelo Conselho Nacional de Assistência Social - CNAS - e Conselho Nacional dos Direitos da Criança e do Adolescente - Conanda -, 2009 enquanto principais ações voltadas à implementação do ECA e ao processo de democratização do Brasil.

Para Klippel e Camargo (2015) a participação política de segmentos importantes da sociedade que propagaram novas ideias sobre educação e cidadania são favorecidas pelas leis afins. Essa demanda confirma as determinações da Lei Orgânica da Assistência Social (LOAS) publicada pelo Ministério da Previdência e Assistência Social, a qual propõe o atendimento assistencial enquanto imprescindível para assegurar a proteção integral e garantir direitos a crianças e adolescentes em situação de risco.

Ao defender a relevância do estabelecimento de uma Cultura da Infância, no qual o haja o amplo resgate da participação infantil, Guerra, (2008) se embasa em pesquisas internacionais como a Convenção pelos Direitos da Criança, realizada em Harvard/EUA (The Political Participation of Children. Harvard Center for Population and Development Studies, 2000). Segundo a autora tal convenção enfatizou a grande participação de crianças, expandindo a concepção de criança enquanto ser humano que demanda proteção e assistência por parte da família, da sociedade e do Estado.

No parecer de Guerra (2008) a criança carece de ser concebida como sujeito de direitos, que deve ter e de expressar opiniões, participar dos processos decisórios e das soluções, bem como, ser parceira no processo de busca por mudanças sociais e na construção da democracia.

Permitir a participação infantil, na concepção de Guerra (2008) é uma forma de lutar contra a desigualdade de poder adulto-criança e o surgimento das diversas formas de abuso físico, sexual dentro do lar, da escola, no trabalho e na sociedade. Para a autora é fundamental no trato com as crianças vitimadas pela violência infantil a consideração da vitima enquanto sujeito que teve seus direitos violados, devido à sua vulnerabilidade ela precisa ser cuidada e protegidas. Ela cita o décimo segundo artigo da Convenção pelos Direitos da Criança como um alicerce do encorajamento aos governos e às organizações governamentais e não governamentais, bem como aos cidadãos comuns a reavaliarem as capacidades das crianças no sentido de envolvê-las nos processos de decisão quanto ao tema.

Rev. Psicol Saúde e Debate. Fev., 2018:4(1):61-84. 
Enfim, a questão da violência infantil é uma problemática ampla e relevante e requer atenção essencial por parte das politicas públicas afins, dos profissionais da saúde e de outros setores, ressaltando nesse contexto o psicólogo.

\section{DISCUSSÃO}

O problema da violência infantil, como fica evidente nas publicações estudadas nessa pesquisa, é amplo e requer atuações coletivas de diferentes segmentos da sociedade, sobretudo dos poderes públicos e dos profissionais que lidam com as crianças vitimizadas.

Nos dizeres de Mayer e Koller (2009) inexiste uma definição universal de violência infantil, pois são vários os termos relacionados a ela como o castigo, a disciplina, os maus tratos, a agressão e/ou a vitimização. Porém é evidente que a violência representa um potencial fator de risco a todas as pessoas, pois ela se vincula a ações capazes de cessar, impedir ou retardar o pleno desenvolvimento humano. Para as autoras a violência se embasa: nas ações caracterizadas por violação dos direitos humanos, abusos das relações de poder como hierarquia, subordinação e desigualdade e nas relações discriminatórias ligadas ao gênero e etnia e de exclusão como a pobreza, marginalidade e orientação sexual.

Assim como as causas da violência infantil, são inúmeros os problemas por ela causados tanto a nível individual quanto a nível social, conforme Mayer e Koller (2009). A cada criança que é submetida são gerados variados transtornos e traumas, e a sociedade inteira é prejudicada pela existência de tal violência.

Klippel e Camargo (2015) mencionam que o enfrentamento da violência infantil necessita, sobretudo, de parcerias relevantes às propostas de intervenção comunitária. É necessária a criação e fortalecimento de redes de atendimento e de suportes e intervenções comunitárias para trabalhar valores como solidariedade e a cooperação entre as pessoas. Nesse sentido tais valores comunitários são apontados enquanto o eixo central que fundamentam as intervenções.

Em conformidade com essa concepção Nunes e Sales (2015) também consideram a necessidade da intervenção pautada na promoção e no resgate dos valores familiares e da coletividade compreendida pelo contexto violento. Eles concebem como essencial a adoção de medidas educacionais em saúde e de modo continuado, pela socialização dos atores envolvidos e, também, o estímulo ao desenvolvimento das políticas sociais de enfretamento à violência. Nota-se a valorização de medidas participativas e cooperativas, de modo a potencializar o enfrentamento da violência e de evitar e/ou combater suas consequências.

Rev. Psicol Saúde e Debate. Fev., 2018:4(1):61-84. 
Bannwart e Brino (2009) defendem a necessidade da reflexão por parte do profissional quanto ao seu papel diante da realidade da violência. Sua percepção precisa superar a equiparação a meros instrumentos transmissores de informações, Ihes possibilitando a compreensão da importância de sua atuação ampliada, a qual não pode se restringir emprego dos procedimentos técnicos, e sim servir à prevenção de problemas afins.

Percebe-se que, no contexto das intervenções de proteção da criança contra a violência e/ou no processo de amenização dos danos por ela causados, a atuação do profissional em Psicologia se evidencia como aspecto de extrema relevância, tendo em vista a importância do conhecimento sobre o comportamento humano. Klippel e Camargo (2015) compreendem como imperativo o empreendimento de esforços na captação e na compreensão da subjetividade das pessoas envolvidas, de modo sensível e humano. Nesse contexto é relevante compreender os sentidos e significados que as pessoas atribuem a si mesmas e às suas próprias condições de vida, sobretudo aquelas geralmente mais excluídas e/ou desvalorizadas socialmente, como as crianças de rua e as que moram em favelas.

Não apenas nos grupos de maior risco, mas em todos os grupos sociais faz-se de grande relevância a atenção por parte da sociedade em sua totalidade. Segundo Bagagi e Paiva (2012), ainda que ainda hajam poucos registros e notificações relativas a problemática da violência contra crianças e adolescentes, as estatísticas principiam a receber visibilidade enquanto uma questão universal que atinge todo tipo de classe social, religião ou sexo. Ou seja, apesar dos avanços encontrados na legislação de proteção da criança, na atualidade ainda persistem casos de violência infantil, e em muitos deles, com extremismos assustadores.

Mayer e Koller (2009) notam os avanços legais ocorridos nacionalmente, mas advertem que mesmo com algumas legislações especificas o problema da violência persiste. Lembrando a criação de vários mecanismos de proteção das crianças, como a Comissão dos Direitos Humanos e o Estatuto da Criança e do Adolescente, cunhados nos últimos anos, tais autoras advertem que ainda assim a violência persiste. A violência doméstica tem sido frequente dentre os fatores de risco para o desenvolvimento na sociedade atual, tais como as agressões verbais, o abuso emocional, físico e sexual, bem como a negligência e o abandono, que por muitas vezes resultam em morte de criança e na impunidade do adulto agressor.

A violência sexual também ocupa espaço de destaque nos estudos, tanto por sua abrangência quanto pelo potencial traumático adjacente. Froner e Ramires (2008) veem como objetivo do Sistema Judiciário buscar a justiça social e garantir o direito dos cidadãos. Assim sendo, na situação da criança sexualmente abusada, os operadores do Direito carecem aplicar a legislação proposta na Constituição Federal e no Estatuto da Criança e do 
Adolescente para garantir a proteção integral da criança e simultaneamente, responsabilizar o agressor.

A escuta das crianças envolvidas no abuso sexual, nos dizeres de Froner e Ramires (2008) corresponde a um direito fundamental em todo o mundo para se chegar á certeza dos fatos ocorridos. Assim na suspeita de abuso e ausência de provas concretas a oitiva adequada da criança se faz potencial instrumento de averiguação dos fatos. As autoras salientam que, além de toda a dinâmica que abrange o fenômeno do abuso sexual intrafamiliar, as declarações das crianças podem se constituir importante referência, e serem decisivas na formalização de uma avaliação judicial.

Certamente a escuta da criança que pode ter sido vitimizada de violência requer uma boa capacidade e formação especifica para a segura compreensão. É fundamental o trabalho coletivo entre profissionais envolvidos na investigação. Mayer e Koller (2009) sugerem um trabalho denominado inserção ecológica no qual a criança e os fatos são considerados no seu contexto. Elas definem a inserção ecológica enquanto o acompanhamento da criança nos seus ambientes naturais (famílias, escolas, comunidades), devendo esse acompanhamento incluir observações, entrevistas, conversas informais e também a aplicação de instrumentos diversificados.

Diante disso, é fundamental que a formação em Psicologia prepare o profissional para uma boa atuação em casos de crianças vitimizada da violência infantil. Na perspectiva da proteção dessas crianças o papel do psicólogo transcende a mera soma de informações obtidas. Froner e Ramires (2008) asseveram ser fundamental a escuta sensível e empática para o alcance do conhecimento da experiência da criança, assim o trabalho interdisciplinar possibilita a proteção dos direitos da criança e também a devida atenção ao seu estado subjetivo, perante as experiências traumáticas.

No intuito da formação de profissionais é de grande relevância somar conhecimentos e competências com um trato multidisciplinar, segundo Froner e Ramires (2008). Elas lembram que os profissionais da área da saúde e operadores do Direito possuem formações distintas que Ihes fazem pensar, sentir e atuar diferentemente ao escutar uma criança. As autoras acrescentam que esse ato requer consideração harmônica e articulada, em sintonia, em cujo contexto precisa estar nitidamente definido e respeitado os limites pelo conjunto de profissionais envolvidos.

Com base nas informações teóricas abordadas é possível considerar que os diversos fatores que influenciam a relação entre o profissional da saúde e a violência infantil se fazem aspecto primordial e requer amplas considerações.

Rev. Psicol Saúde e Debate. Fev., 2018:4(1):61-84. 
Relativo à temática Bannwart e Brino (2009) salientam que, em geral, os profissionais da saúde, devido à sua formação e ao modelo de atuação vigente, lidam cotidianamente no trabalho, com diversas dificuldades no enfrentamentode casos suspeitos ou confirmados de maus tratos. Dentre tais dificuldades elas citam as lacunas na formação profissional, as ideias pré concebidas, inabilidade para lidar de forma global com a questão, medo de processos ou represálias, a obrigação de se ter certeza sobre a ocorrência. $E$ defendem a inserção e permanência de tais profissionais em cursos de capacitação continuada.

Na concepção de Klippel e Camargo (2015) cabe aos profissionais investirem na sua própria formação e se atualizarem constantemente. Outro fator de extrema relevância está na ética na profissão, cuja delicadeza dessa questão requer expressiva atenção a esse fator. A autora considera fundamental ao discutir as relações entre investigação e intervenção dentro das práticas comunitárias, valorizar e promover reflexões relativas aos cuidados éticos inerentes à adequada realização de trabalhos dessa natureza. Assim é imprescindível considerar o contexto das relações comunitárias.

Partindo dos pressupostos estudados é concebível como o mais importante no trato com a violência infantil a percepção do problema em sua totalidade. Porém, não basta julgar os profissionais e criticar sua formação, é imperativo o engajamento social na busca por soluções eficazes no combate a violência infantil. Enfim, a proteção da criança é inerente à proteção da sociedade enquanto um todo, pois a violência infantil ocorre sempre dentro de um contexto, assim sendo todo esse contexto precisa ser transformado para que haja a ruptura com essa prática.

\section{CONSIDERAÇÕES FINAIS}

A literatura destaca o fenômeno mundial e crescente da violência infantil havendo a necessidade de ações preventivas junto à família, comunidade e sociedade em geral. $\mathrm{O}$ enfrentamento dessa problemática é uma questão complexa e multidimensional que requer atenção prioritária e ações eficazes.

Fica evidente que a violência infantil advém da história da evolução humana e mesmo com legislação específica de proteção integral a criança, é uma realidade que carece de muitos esforços para que seja superada. É também notório que os problemas psicológicos advindos dela, se fazem fator de risco ao pleno desenvolvimento da criança e do adolescente.

O psicólogo tem muito a contribuir tanto na prevenção da violência infantil quanto na minimização dos danos dela advindos. Entretanto, é fundamental que variados setores e

Rev. Psicol Saúde e Debate. Fev., 2018:4(1):61-84. 
categorias profissionais sejam envolvidos diante da magnitude dessa problemática. Além disso, é necessário que todos sejam os coparticipantes na proteção dos direitos das crianças e adolescentes, pois o trabalho de equipe se faz o diferencial no processo de auxilio às vitimas dessa triste realidade.

Certamente o tema necessita de reflexões mais abrangentes, assim sendo esperase que novas abordagens afins venham apresentar possibilidades de prevenção e intervenções eficazes pelo bem da sociedade em geral, sobretudo, das crianças, cidadãos de direitos, os quais muitas vezes ignorados.

\section{REFERÊNCIAS}

Bagagi, P. Paiva, C. N. (2012) A atuação dos profissionais de saúde nos casos de violência contra crianças e adolescentes. Revista Científica Eletrônica de Pedagogia, Garça, 10(1) 1.

Balbinotti, C. (2008). A violência sexual infantil intrafamiliar: a revitimização da criança e do adolescente vítimas de abuso. Direito \& Justiça, 35(1).

Bonvicini, C. R. \& da Silva, J. C. (2015) Violência e promoção da saúde. Psicologia e Saúde em Debate. 1. (1) 78-88.

Camargo, D. D. (2015). Processo participativo entre profissionais de saúde para integrar o atendimento à criança vítima de violência. Pesquisas e Práticas Psicossociais, 10(2), 340353.

dos Deputados, B. C. (2010). Estatuto da criança e do adolescente: Lei n. 8.069, de 13 de julho de 1990, e legislação correlata. In Legislação (Vol. 25). Centro de Documentação e Informação.

ESTATUTO, D. C. E. D. A. (1990). Ministério da Justiça, Secretaria da Cidadania e Departamento da Criança e do Adolescente.

Faleiros, V. D. P., \& Faleiros, E. S. (2008). Escola que protege: enfrentando a violência contra crianças e adolescentes. In Escola que protege: enfrentando a violência contra crianças e adolescentes, 98.

Machado, J. A., \& Sanches, M. A. (2014). A Gênese da Violência Infantil. Caderno teológico da PUC, Curitiba 은 (1), 173-189.

Mayer, L. R., \& Koller, S. H. (2012). Rede de apoio social e representação mental das relações de apego de crianças vítimas de violência dome'stica. Violência Contra Crianças e Adolescentes. Teoria, pesquisa e prática, 55-68.

Nascimento. S. A. V. (2009). Violência intrafamiliar e a síndrome do segredo. Revista do Ministério Público de Goiás, Goiânia 12(17), 33-40.

Nunes, A. J, \& Sales, M. C. V. (2015). Violência contra crianças no cenário brasileiro. Ciencia \& saude coletiva, 21(3), 871-880.

Rev. Psicol Saúde e Debate. Fev., 2018:4(1):61-84. 
Papalia, D. E., \& Feldman, R. D. (2013). Desenvolvimento humano. Artmed Editora.

Pereira Alberto, M. D. F., Rodrigues de Almeida, D., Chacon Dória, L., Cavalcanti Guedes, P., Ramalho de Sousa, T., \& Pessoa de França, W. L. (2008). O papel do psicólogo e das entidades junto a crianças e adolescentes em situação de risco. Psicologia Ciência e Profissão, 28(3).

Petry Froner, J., \& Röhnelt Ramires, V. R. (2008). Escuta de crianças vítimas de abuso sexual no âmbito jurídico: uma revisão crítica da literatura. Paidéia, 18(40).

Severino, A. J. (2017). Metodologia do trabalho científico. Cortez editora.

Soares, G. R. \& Mendes, D. F. (2017) A atuação do psicólogo com adolescentes infratores em medida socioeducativas. Psicologia e Saúde em Debate. 2. (Ed Esp. 1)117-137.

Veloso, M. M. X., Magalhães, C. M. C., \& Cabral, I. R. (2017). Identificação e notificação de violência contra crianças e adolescentes: limites e possibilidades de atuação de profissionais de saúde. Mudanças-Psicologia da Saúde, 25(1), 1-8. 